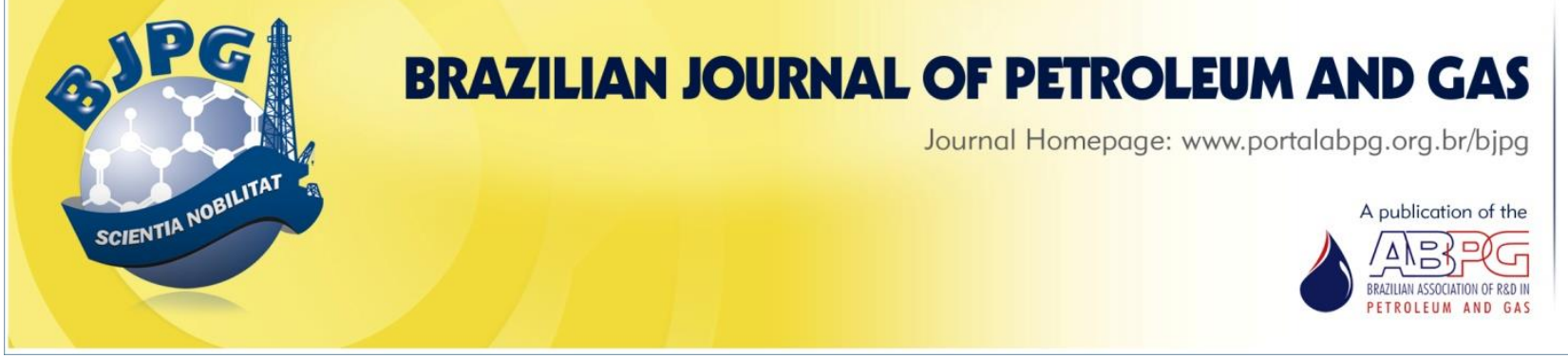

\title{
A REVIEW OF THE POLITICAL AND ECONOMIC IMPACTS CAUSED BY THE RECENT CHANGES IN THE REGULATORY FRAMEWORK OF THE OIL AND GAS SECTOR IN BRAZIL
}

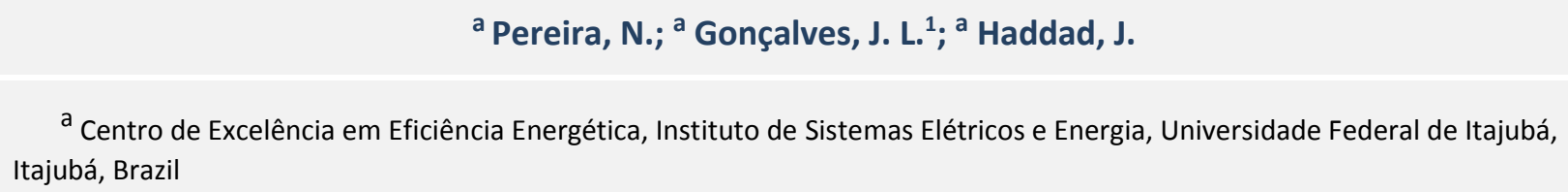

\section{ABSTRACT}

The discovery of oil and gas in the Brazilian Pre-salt led to the mobilization of the Brazilian political and economic sectors. With the goal of capitalizing on the Pre-salt, and maximizing growth opportunities, the Federal Government implemented changes in energy-related regulations. In this regard, this paper reviews the main economic and political impacts caused by the changes in the Brazilian regulatory framework that took place in 2010. It also discusses these changes in light of Federal Law 9.478, that went into effect in 1997, the so-called "Brazilian Oil Law". A primary study was performed in order to gather the implications of this change considering, as major economic factors, oil and gas production, government revenues, modification of sectors which make up the gross national product (GNP), the delay of Pre-salt exploration and production, and investments in research, development, and innovation. As political factors, the following aspects were analyzed: political instability, creation of "Pré-sal Petróleo S.A.", and capitalization of Petrobras. At last, this paper discusses the positive and negative aspects related to each relevant factor.

\section{KEYWORDS}

Pre-salt; oil, gas; Brazilian regulatory framework

\footnotetext{
${ }^{1}$ To whom all correspondence should be addressed.

Address: Centro de Excelência em Eficiência Energética, Instituto de Sistemas Elétricos e Energia, Universidade Federal de Itajubá. Av. BPS, N 1303, Pinheirinho, Itajubá, Brazil e-mail:nicoleparreira@yahoo.com.br; joseluiz@unifei.edu.br; jamil@unifei.edu.br doi:10.5419/bjpg2014-0015
} 


\section{INTRODUCTION}

The great discoveries of oil and natural gas in "Pre-salt" have placed Brazil in an important position in the international political and economic scenario. Today, the production in this region has already reached 412 thousand barrels per day (March/2014), and this number is expected to continue to grow. By 2017 the Pre-salt should be producing more than one million barrels, doubling the national production by 2020 . It also brings the possibility of increasing the current reserves from 15 billion to around 100 billion barrels (Petrobras, 2013).

Bearing in mind these perspectives, besides the excellent quality of the oil and the high success index on the drillings, in 2010 there was the need of changing the exploration and production laws for the referred areas, under the argument that the Brazilian Oil Law (Law 9.478/97) was elaborated in a time when the country depended on oil importation and presented high exploratory risk. Thus, the Brazilian Government changed the regulatory framework and implemented a new model with the objective of increasing the governmental stakes, keeping the attractiveness for investors, and redistributing the gains originated from the oil production across the Brazilian society.

Although some of these changes may be favorable to Brazil, they are also followed by uncertainties and challenges, since it is not an easy task to change an entire legislation which traditionally has had positive impacts over the oil and gas sector of the country. In this context, one of the innovations of the new regulatory framework is the alteration of the concession model by the production apportionment in the Presalt areas, having as main characteristic the sharing of the production between the Country and the contracted party. One of the benefits of this model is providing the State with a larger stake and with the control of the exploration and production activities. On the other hand, this may impair the investments in the Country, taking into account the decay in competitiveness and attractiveness.

However, in the oil and gas sector, the repercussions caused by these types of regulatory alterations can only be observed in medium and long terms, generating either satisfactory results or catastrophic and near irreversible results. The description and follow-up of these repercussions are essential to make market projections as well as informing citizens and companies interested in the sector. In this sense, this paper studies the main economic and political impacts caused by the change of this regulatory framework in Brazil.

\section{METHODOLOGY}

The reviewing process was made in two steps. Initially, a study was performed on the potential factors that could present repercussions coming from the alteration of the regulatory framework. In the second step, the positive and negative aspects were reviewed in the literature considering each potential factor. This review used data from Brazilian government official websites publications of experts in the subject, and scientific predictions based on mathematical models. Table 1 shows the factors identified in the first step. The following section presents the analysis results of these factors.

Table 1. Factors commonly identified as most sensitive to the change of the regulatory framework.

\begin{tabular}{l|l}
\hline \multirow{4}{*}{ Economic impacts } & Oil and natural gas production \\
\cline { 2 - 2 } & Governmental stake \\
\cline { 2 - 2 } & Gross domestic products sectors \\
\cline { 2 - 2 } & Pre-Salt development rate \\
\cline { 2 - 2 } & Symptoms of the “Dutch Disease" \\
\cline { 2 - 2 } Political impacts & Investment in research and development \\
\hline & Political instability \\
\cline { 2 - 2 } & Pré-Sal Petróleo S.A. \\
\cline { 2 - 2 } & Petrobras capitalization \\
\hline
\end{tabular}




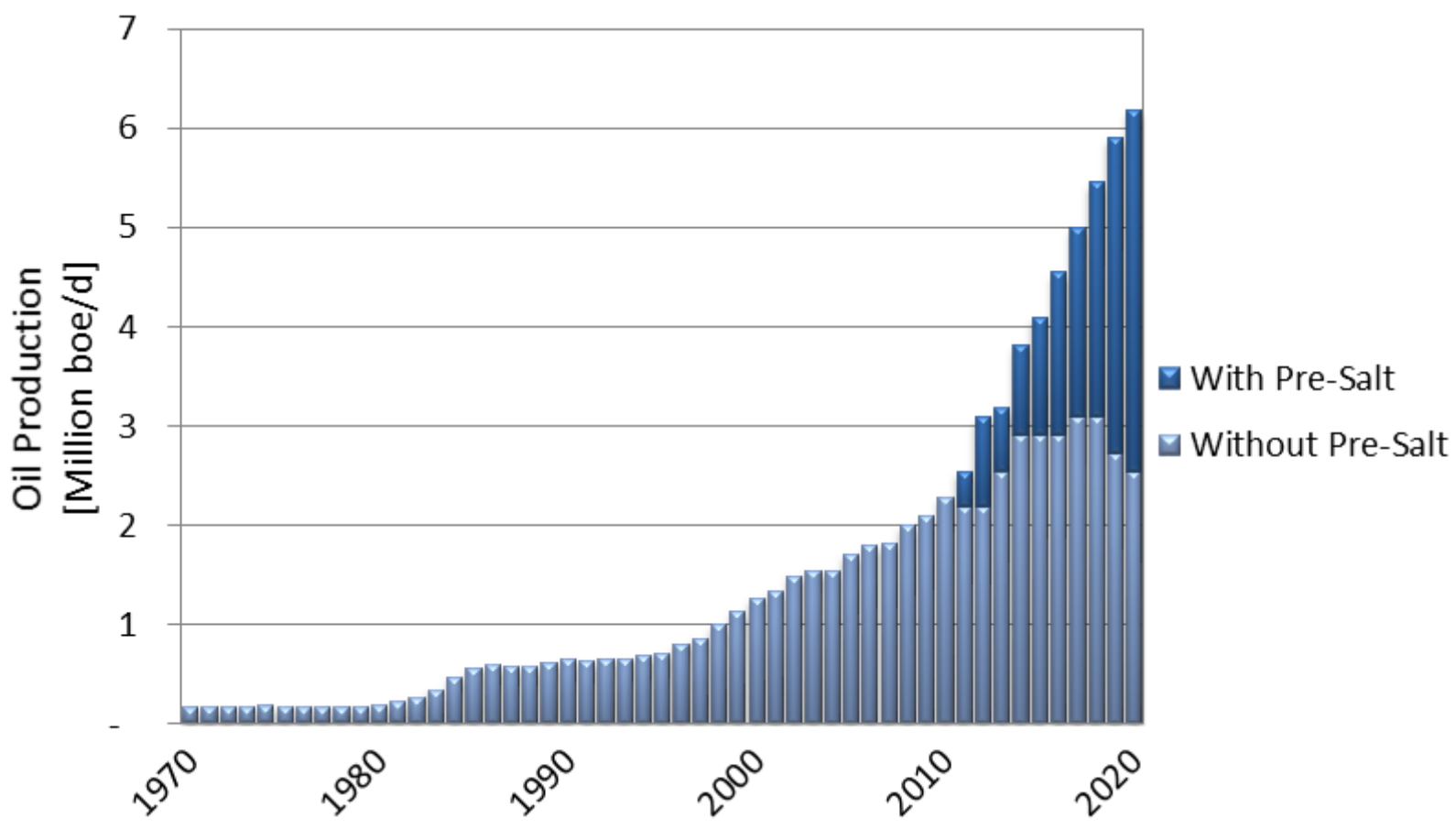

Figure 1. Evolution and forecast of oil and natural gas production in Brazil. Source: Adapted from Magalhães and Domingues (2012) and ANP (2012).

Concerning the economic aspects, we analyzed the impact of the modifications in the regulatory framework pertaining the oil and natural gas production, since other factors are related directly to production, such as the government stake and the Gross Domestic Products (GDP) sectors. It is important to highlight that the repercussions caused by alterations of market strategy and regulatory models can only be observed in a long term, with the possibility of generating either positive or catastrophic and hardly reversible results. However, after more than 16 years of the promulgation of the Oil Law, the main effects of this law were also assessed to reflect upon the feasibility of implementing changes in strategies changes and regulation models.

Nevertheless, some repercussions coming from this change of framework can already be observed. Technology developments in ultra-deep waters by Petrobras, delays on bidding rounds, and investments in preferential sectors that compound the Gross Domestic Product (GDP) are good examples of areas affected by this change. The latter, particularly, may have their sectors changed by the preference for investments focused in some of these sectors, since the aggregate amount of the GDP is equal to the sum of private consumption, total investments, government expenditures, and net balance between exportations and importations. This may have a negative impact on the Country and lead to a deindustrialization process, known as "Dutch disease". Evidences of this effect were found due to be connected to these events.

\section{ANALYSIS OF THE ECONOMIC IMPACTS}

\subsection{Oil and natural gas production}

One of the main sectors affected by political and economic changes is the oil and natural gas production, which, however, requires medium and long terms to be noted. In this sense, the production in Brazil has experienced a period of great prosperity during the opening process, authorized by the constitutional amendment 9/95 (Figure 1).

Under the current concession model, that brought competitiveness to the domestic market, 11 bidding rounds were performed for exploratory areas, attracting investments from international companies, strengthening Petrobras, and enabling the creation of national companies. The intense oil exploration activities performed by these companies, mainly in maritime environments, 


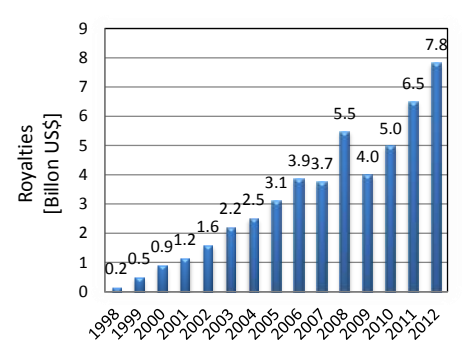

(a)

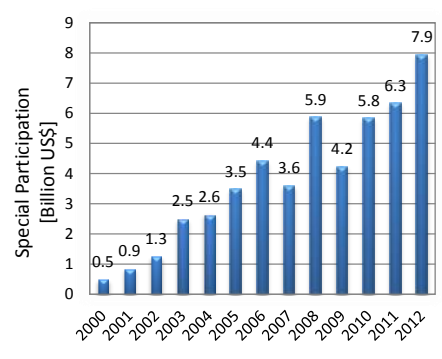

(b)

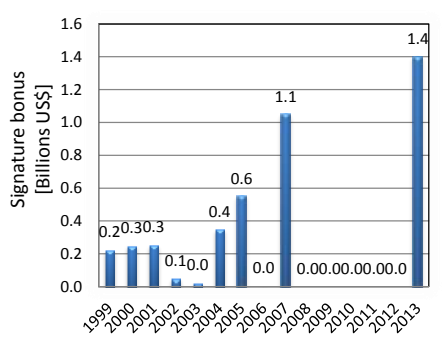

(c)

Figure 2. Governmental participation in the concession model as: (a) royalties, (b) special stake, and (c) signature bonus.

Source: ANP (2012)

resulted in the expressive increase of Brazilian oil reserves, from 6.1 to 15.3 billion barrels. These reserves are found mainly in the Southeastern region of Brazil (Perobelli and Oliveira, 2013). Considering the whole national territory, in the last 10 years there was an annual average growth in production of $4.2 \%$, placing Brazil in the $13^{\text {th }}$ position in the world ranking of oil producers in 2012 (ANP, 2012).

The expectation is that, even with the change in the regulatory framework, there will be an increase in the total production of oil and gas in the next years, as one can see in Figure 1. In 2014, the contribution of Pre-salt surpasses the production of other national reserves, such as inland. Taking into account the production of the Pre-salt fields, according to the forecasts of the 2008-2017 TenYear Plan of Energy Expansion (PDE), these areas alone will allow the country to reach the average production of around 3.4 million barrels/day of equivalent oil in 2017. This change will elevate Brazil to the condition of sixth biggest world producer. If this forecast materializes, Brazil will be a condition of oil exporter, becoming an important player in the world's energetic sector and causing a great impact in tax revenue and in different sectors of the national economy.

\subsubsection{Governmental participation}

In the areas under the concession model, the increase in oil production will also increase governmental levies. According to the Oil Law, government participation is divided in four modalities: royalties, special participation, signature bonus, and payment by the occupation or retention of the area. The governmental stake caused, from its validity, a vigorous implement in the public revenues of this kind, according to Figure 2.

In the new regulatory framework, which adopts the production apportionment regimen in the Presalt area, royalties and bonus execution will be the only ones in use. The special stake was set aside by the legislator and an "oil surplus" institute was created with identical essence. The Oil Law reverberated positively in the oil and gas sector, increasing government's levies (Figure 2), investments, proven reserves, and production.

However, the suspension of the auctions for almost five years (Figure 2c) destabilized the sector. In this period, the shale gas gained relevance in the market and significant investments were made in other countries, such as in Africa. If the existent model was adopted (Law 9.478/97) for exploring and producing oil in these areas, the trend would be to keep investments and levies, promoting a superior increase in production and volume of the proven reserves. These factors indicate that the modification of the regulatory framework seems to be more related to political interests than to economic interests.

\subsection{Main sectors of the Gross Domestic Product (GPD)}

When there are great oil discoveries in a country, the preference for investments in this sector naturally occurs, affecting all the other sectors that comprise the GDP. Developed countries can be de-industrialized by a process known as "Dutch disease" while poor countries are 
Table 2. Investments mapped in the Brazilian Industry from 2011 to 2014.

\begin{tabular}{ccc}
\hline Sectors & Billions [US\$] & [\%] \\
\hline Oil and gas & 189 & 61.5 \\
\hline Mineral Extraction & 31 & 10.2 \\
\hline Steel Metallurgy & 16.5 & 5.3 \\
\hline Chemicals & 20 & 6.5 \\
\hline Paper and Cellulose & 14 & 4.5 \\
\hline Vehicles & 16.5 & 5.4 \\
\hline Electro-Electronics & 14.5 & 4.8 \\
\hline Textile and Clothing & 6 & 1.9 \\
\hline
\end{tabular}

Source: BNDES (2011)

not able to technologically develop a process known as the "oil curse". In this sense, three years since the change of the regulatory framework, efficient policies for fighting these effects have not been observed. More participation of the Government along with Petrobras has provided great investments in the oil and gas sector, and has left other important sectors for the development of the country (Table 2 ).

Table 2 shows that, between 2011 and 2014, the investments in the oil and gas sector corresponded to more than $60 \%$ of the investment of all the industrial sectors in Brazil, characterizing the first step in the development of the "Dutch disease". Taking into account the current scenario, Magalhães and Domingues (2012) foresee that some of the sectors will be negatively affected, such as the machine and equipment, ferrous metals, leather articles and shoes, transportation equipment, wood production, and electronic equipment. These sectors are part of the transformation industry, the main source of the development of a country. On the other hand, the sectors of the GDP related to exploration and production of oil and natural gas, refining of oil and chemical products, and production of plastics will be benefitted, causing positive impacts also along the whole supplying chain and highlighting capital goods, employment, and knowledge industries.

The preference for investing in the oil sector may have both positive and negative aspects, despite the change in the regulatory model.
However, this de-industrialization process may be a source of concern in case there is a disordered injection of funds from exploratory activities, in which case the Government would have to take measures to soften this effect.

\subsection{Pre-salt development rate}

The stagnancy of the exploration and production processes in the Pre-salt started just before the ANP's ninth bidding round, when the CNPE ordered that the ANP withdrew 41 exploratory blocs of high oil potential out of the ninth round. However, the withdrawal of the blocs brought polemic and criticism, besides resulting on the weakening of that bidding round, as well as causing the withdrawal of a large number of big companies from the auction (Vazquez, 2010). From that moment on, the investments of those companies in other countries was favoured. This action has damaged the Brazilian economic sector, since the bidding rounds generate positive and continuous effects in the public revenues, increasing the country's reserves and bringing considerable governmental levies. This was evidenced in the $11^{\text {th }}$ bidding round performed on March 14 ${ }^{\text {th }}, 2013$ that broke the record of execution bonus levy (US\$ 1.4 billion) for exploration in other Brazilian areas.

In the first auction performed under the apportionment model, occurred in October 2013 for the Libra Bloc, there was only one offer proposed by the Company consortium Petrobras 
(40\%), Shell (20\%), Total (20\%), CNPC (10\%), and CNOOC (10\%). In spite of this single offer, the execution bonus was the biggest in history ( US\$ 7.5 billion), and Brazil significantly increased its tax collections related to the production (between $60 \%$ and $84 \%$ of the production). However, the great deadlock was caused by the suspension of the auctions for almost five years, which resulted in destabilization and the continuity of the investments in the sector.

The excessive attributions assigned to Petrobras, based on the new model, have contributed to the delay of the Pre-salt development. Besides the obligation of the Company to participate with at least $30 \%$ of the region's bloc, Petrobras would also have to invest in the exploration and production in the Post-salt regions, and in refinery and distribution. In the 2011-2015 Business Plan, Petrobras aims to invest less than a half of the amount expected (US\$ 224.7 billion) in Pre-salt development (45\%), mainly due to the obligation to investment in the Post-salt area, its main source of income.

The justification for the investment was based on the fact that, since 2010, the Company counts on its own capital, which comes from the net earnings, for Pre-salt investments

To change the current framework, Petrobras will also invest in the refinery park for reducing importations, increasing revenues and filling the demand for by-products in the domestic market. Nevertheless, market value drop, price policy, and losses in the importation of oil products contributed to the reduction of investments in the region.

\subsection{Threat to research, development, and innovation investments}

In the concession model from Law 9.478/97, the concessionaires must invest one percent of the gross billings of the high productivity oil fields in research, development, and innovation (R,D\&I). Over the years, this investment generated a gradual increase in the demand for product development projects done in collaboration with companies and universities. The referred contractual clause also assured the duration of the Petrobras Research Center (CENPES) and established a minimum value of $50 \%$ assigned to Universities, making possible the inclusion of important programs, such as the PROMINP (Oil Industry Mobilization Program), the PRH (Human Resource Program), and the PFRH (Petrobras Program for Human Resource Formation). These programs account for much of the demand for qualified professionals in the sector, indicating that Brazil has conditions of filling the existing gap and developing its manpower through a coordinated industrial policy.

With the new regulatory model, the continuity of fund's application coming from royalties and special stake in the oil and gas sector is threatened. In this model, these resources are intended for a social fund, which will be distributed to other sectors such as health, education, culture, science, and technology. The exact percentage to be invested in research, development, and innovation remains unclear, threatening the continuity of the development obtained so far. It is crucial to specify, in this new regulatory framework which will be the resources destined to the R,D\&l sector, considering that the Brazil could use the opportunity offered by the discovery of these reserves for developing its innovation capacity and improving the quality of its workforce.

\section{ANALYSIS OF POLITICAL IMPACTS}

\subsection{Political instability}

The creation of the new regulatory framework during the current political administration (PTWorkers Party) assumed that the concession model was established in a time of geological uncertainties and high exploratory risks. In contrast, in Pre-salt regions, the associated oil availability was amazing and the exploratory success was absolute, justifying the increase in government levies and stake. However, according to Lucas (2012), this alteration of the regulatory framework is more associated with political than with economic interests. For this author, if the administration's objective was to increase government's levy, it would suffice to increase royalties' and special stakes' aliquots. Besides, the newly created 'oil surplus', which deducts part of the extraordinary income obtained from the most profitable fields, has the same material purposes of old 'special stake', changing only the nomenclature. The third evidence is associated 
with the direct involvement of the government with Petrobras through its capitalization. At last, another factor is linked to the creation of "Pré-Sal Petróleo S.A. (PPSA)", a state-owned company that will manage agreements, having roles that might superpose ANP's ones. This alteration of the regulatory framework caused reverse effects such directly experiencing risks associated with the oil trade, administrative difficulties within Petrobras' management, delays in the bidding round, and questioning of the feasibility of the PPSA creation.

The risks associated with the way of collection, in the apportionment agreement, exist because the Government gets its part in oil. This forces the administration to participate in the oil trade directly, being subjected to market risks. Besides, the agreement projects a situation where there would be no comparative parameters for exploration and production costs, highly increasing the uncertainty and distrust of investors.

Another reverse effect is related to the difficulties faced by the current management at Petrobras, and the delays in the Pre-salt bidding rounds. The legal obligation of participating in all the consortiums as an operator, imposed by the apportionment model, created a serious concern to the Company's management team because the Government will have to open new bids. If so, Petrobras will have to associate itself to winning companies in less attractive areas, since the Company is already overburden with the activities foreseen in the 2013-2020 business plan and with the activities in exclusive areas (onerous assignment).

\subsection{Political impact of the Pré-Sal Petróleo S. A.}

Three years have passed since the creation of the Pré-Sal Petróleo S.A. (PPSA) and the company is still under a structuring phase. In October 2013, the president of the company (Mr. Oswaldo Pedrosa Júnior) and three other chief officers were assigned by the political administration, PT, without any market rejection. It is still missing the definition of the company's structure, the members of the administration, numbers of employees, way of action, and assignments before ANP and Petrobras.

It is observed that one of the main impacts caused by the creation of PPSA is the compression of ANP's institutional space, somehow taking away its regulatory authority. In this sense, the institution of the PPSA causes concern, not only because of the extinction of the regulatory role of ANP, but also due to the possible mitigations of this action in the Pre-salt context. Both Law 12.304/10, that created PPSA, and Law 12.351/10, that establishes the Pre-salt exploration and production activities and introduces the production apportionment regimen, raise questions on the action of ANP in the Pre-salt. The latter might particularly cause major concerns because it widens the action of the CNPE and the MME, and changes the capacities granted to ANP by the Oil Law.

\subsection{Petrobras capitalization}

It is known that the market is sensitive to shortterm fluctuations, a fact which could be verified after the Petrobras capitalization process. At the time, there was a reduction of the Company's market value and consequent drop of the stock exchanges (Figure 3). However, in the long term, it is certain that Petrobras will substantially increase its proven reserves and the daily production of oil, gas, and by-products, changing the current economic scenario.

In regards to the Company's market value, Figure 3 illustrates the variation of its shares from 2000 to 2014, and compares it along with those of four other companies of the sector.

An expressive increase in value is observed in Petrobras' stock exchange from 2006 and 2008, mainly due to the positive Pre-salt expectations combined with high oil barrel prices, that reached US\$ 50.00 (converted 2 BRL = 1 US\$) in April 2008. Since then, the values of Petrobras and other companies of the sector had their values affected mainly by the world economic crisis. Although this crisis has affected the values of the great oil companies, most of them have recovered. Companies such as Exxon Mobil and Conoco have a current market value very close to the one of 2008, when they reached the highest value in history, with differences of only approximately $8 \%$ and $3 \%$ if compared to 2008 , respectively.

Since the rise in 2008, Petrobras lost more than $75 \%$ of its market value (from March/2008 to December/2014), having the biggest drop among the top world oil companies. The key reasons associated with this drop in value were the high 

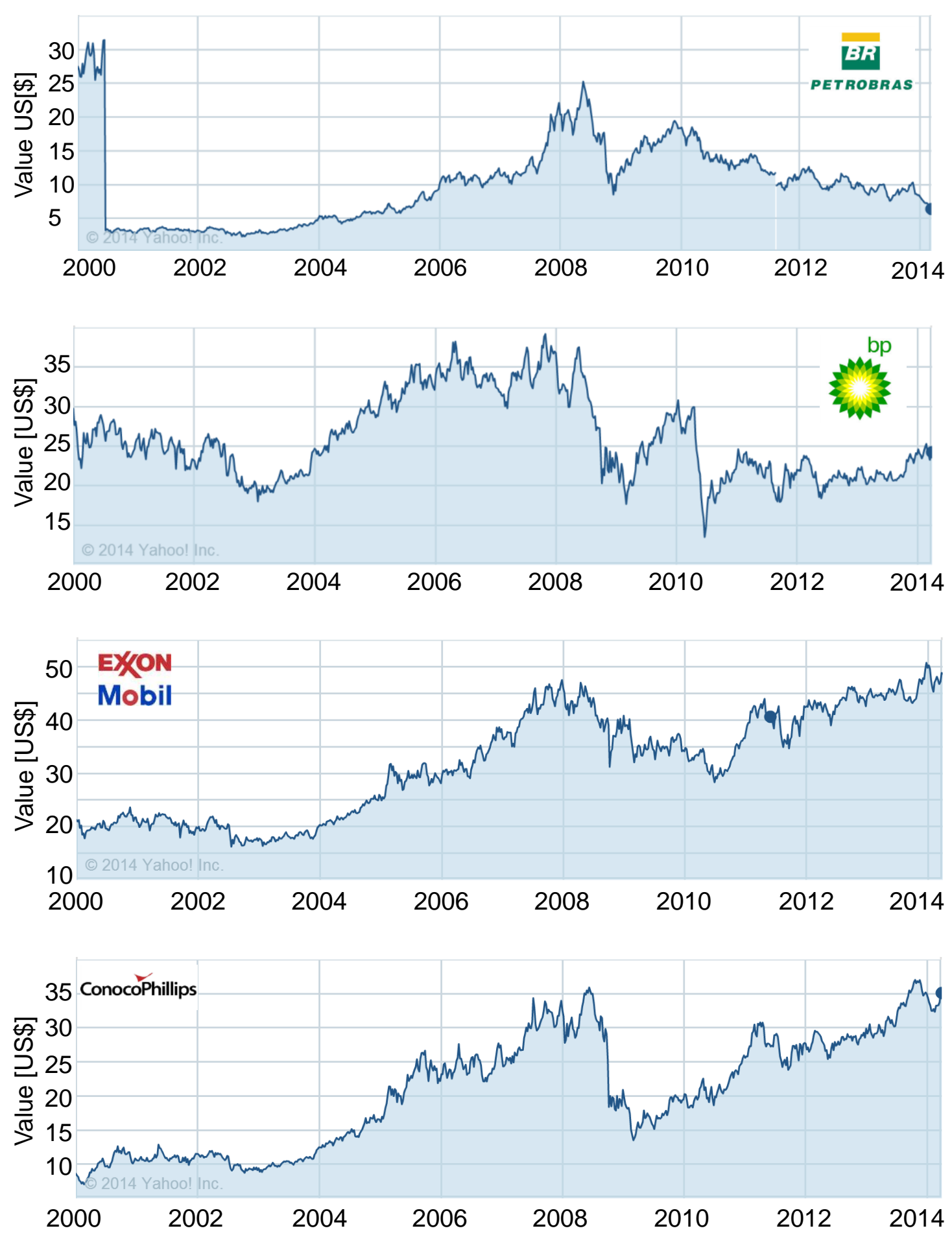

Figure 3. Stock exchange fluctuations of some companies from oil and gas sector (2 BRL = 1 US\$). Source: Adapted from YAHOO FINANÇAS (2013).

level of political interference in the company and Brazil's increase in fuel imports. The reason behind the increase in fuel demand in part was propelled by the subsidy provided by the government for the sale of vehicles, by means of tax reduction (particularly the IPI- "Tax over Industrialized
Products"), which caused the importation of a large volume of oil products, mainly diesel oil and gasoline. Besides, the Government and Petrobras have a price policy whereby the company does not pass immediately on to the final consumer the oscillations in oil price experienced by the 
Table 3. Main repercussion of Petrobras after the capitalization process.

\begin{tabular}{l|l}
\hline \multicolumn{1}{c|}{ Positive repercussion } & \multicolumn{1}{c}{ Negative repercussion } \\
\hline $\begin{array}{l}\text { Possibility of expressive valuation of its shares and } \\
\text { its market value after increasing its reserves and } \\
\text { reaching the production goal in 2017. }\end{array}$ & $\begin{array}{l}\text { Disrespect with the minority investors and lack } \\
\text { of rectitude has caused the Company to have a } \\
\text { negative image. }\end{array}$ \\
\hline $\begin{array}{l}\text { Benefits coming from synergy with other } \\
\text { companies in the development of several fields. }\end{array}$ & $\begin{array}{l}\text { Division of the dividends with higher number of } \\
\text { shareholders and long-term return. }\end{array}$ \\
\hline $\begin{array}{l}\text { Development of state-of-art technologies for } \\
\text { exploration and production in ultra-deep waters. }\end{array}$ & $\begin{array}{l}\text { High costs, low efficiency influence of the } \\
\text { Government. }\end{array}$ \\
\hline
\end{tabular}

international market. Such policy may lead, potentially, to more damage to the Company's funds.

Conversely, the direct involvement of the Government in the decisions of the State-owned company had great repercussions, making possible for the company to increase the capacity of investment while increasing the uncertainties for investors. One can observe that the capitalization process provided Petrobras with the possibility of increasing its reserves and technological potential; the legislator created a market reserve for Petrobras. In Pre-salt areas, Petrobras has the privilege of taking at least $30 \%$, without bidding, in apportionment contracts and of being the sole operator in the fields assigned to onerous assignment (cessão onerosa ${ }^{2}$ ).

These privileges are followed by political interests, and the Company has its decisions affected tremendously when the Government is allowed to increase its stakes. This involvement happened with the purchase of Petrobras' shares, where the Federation acquired all the shares it was entitled to for being in a shareholder along with the unsubscribed shares from shareholders that did not perform their subscription right. For paying up its stake in the public offer of shares, the Federation transferred to Petrobras almost US\$ 34 billion in Treasury Bonds (LFT). In exchange,

\footnotetext{
2 The Union [the federal government] is authorized to onerously assign to Petróleo Brasileiro S.A. PETROBRAS, without the need to bid, the right to research and extract oil, natural gas and other hydrocarbon fluids, in areas not subjected to concession contracts, located in Pre-salt reservoirs.
}

Petrobras got the right to explore and produce in the assignment areas, being able to extract a volume up to five billion barrels of equivalent oil, to an average price of US\$ 8.51 , with variations among the fields.

In summary, these activities enabled the Federation to keep titles of its own debt and Petrobras' shares, widening its shareholder stake without the need of disbursing fiscal funds. The investors purchased their shares with monetary resources, and Petrobras kept the oil and the monetary resources, besides widening its capital stock.

As a result of this capitalization process, a dilution of the shareholder's stake of minority shareholder, the national natural persons, which made possible the increase of the participation of the Federation, also computed the participations of BNDESPAR (National Bank of Economic Development and Social Stakes), BNDES (National Bank of Economic and Social Development), and Sovereign Fund in the company, passing from $39.8 \%$ to $48.3 \%$ of its total capital. This has reduced the power of vote of the minority shareholders, as well as the incomes coming from the exploration and production, having a negative impact over the image of the Company. Table 3 summarizes the main repercussion of Petrobras' capitalization.

\section{CONCLUSIONS}

In this paper the main economic and political impacts caused by the change of the Pre-salt regulatory framework, and the repercussions 
brought about by the Oil Law (Law 9.478/97) were discussed. Therefore, as main results, one may list:

- The Oil Law (9.478/97) has positively reverberated in the economic sector of the country, particularly bringing regulatory stability, legal security, respect to the market rules, and expressive increase of the governmental collections;

- Positive and negative impacts over the sectors of the gross domestic product (GDP) are associated with the Pre-salt development. The de-industrialization process may be a source of concern in case there is a disorderly injection of funds of exploratory activities, and the Administration would have to take measures to avoid this effect;

- The suspension of the bidding rounds for five years impaired significantly the investments in the oil and gas sector in Brazil;

- The resources coming from the royalties and special stakes will be destined for a social fund, threatening the continuity of the application of these funds in research and development;

- The alteration of the regulatory framework seems to be more associated with political than with economic interests;

- The capitalization process experienced by Petrobras enabled to the Company to increase its investment capacity but, on the other hand, reduced its market value mainly due to the Brazilian government intervention;

- In the end, under the same mixed regimen, the expectation is that Brazil becomes one of the seven biggest oil producers until 2020.

\section{ACKNOWLEDGEMENTS}

The authors are thankful to the financial support of the National Agency of Oil, Natural Gas and Biofuels- ANP for sponsoring the Program of Human Resources for the oil and gas sector PRH/FINEP/MME.

\section{REFERENCES}

ANP, National Petroleum Agency. Brazilian Annual Report of Petroleum, Natural Gas and Biofuels. Rio de Janeiro, RJ. 2013. In: http://www.anp.gov.br/?id=548. 01 April 2013.

Lucas L. P. V. A derrota de um modelo de sucesso. Petróleo: Reforma e Contrarreforma do setor petrolífero brasileiro. Rio de Janeiro, RJ, Brazil. Ed. Elsevier. 2012.

Magalhães A. S.; Domingues, E. P. Benção ou maldição: impactos do Pré-Sal na indústria brasileira. White paper. Prêmio CNI de Economia 2012. Categoria: Economia Industrial. In: http://arquivos.portaldaindustria.com.br. 2012.

Perobelli F. S.; Oliveira, C. C. C. Energy development potential: an analysis of Brazil. Energy Policy. N 59. p 683 - 701. 2013. http://dx.doi.org/10.1016/i.enpol.2013.04.023

Petrobras. Produção no Pré-Sal bate novo recorde e alcança 300mil barris de petróleo por dia. White paper. In: http://fatosedados.blogspetrobras.com.br. 2013.

Vazquez F. A. Análise crítica das ofertas das rodadas de licitações da ANP, com foco nas variáveis do julgamento do processo licitatório: conteúdo local, bônus de assinatura e programa exploratório mínimo. Trabalho de Graduação. 97 p. Universidade Federal do Rio de Janeiro. Escola Politécnica. Rio de Janeiro. 2010. 